\title{
Natural Achievements: Lesbian Mothers in American Culture
}

In the years since I began $m \gamma$ interviews, the study of lesbian and gay people and communities has grown, in anthropology as well as in history, sociology, and literature. Much of this new scholarship has been carried on by researchers who do not hesitate to identify themselves as gay or lesbian, or whose sympathetic stance is clear. Certainly little of this new work is informed by older models of deviance and abnormality, and virtually none of it is built around the questions central to earlier approaches which aimed at "explaining" homosexuality. ${ }^{1}$ Though these writings are quite diverse in both subject matter and theoretical perspective, they are unified by their concern to define the multitude of worlds that can be called, on some basis, lesbian or gay.

While the new lesbian and gay scholarship has tricd to avoid the kind of determinism and orientation toward pathology that distorted earlier work, and has offered views that contradict the facile essentialism of much popular writing, I think it nonetheless has failed to take full account of the ambiguities, areas of overlap, and occasional blurring of boundaries between gay/lesbian and heterosexual experience. If a study of lesbian mothers does anything, it forces us to confront the issue of boundaries, to understand definitively that most of the categories that shape our work should be treated with skepticism. Despite the efforts of E. R. Leach and Fredrik Barth years ago to see social and cultural categories as ephemeral and negotiated, ${ }^{2}$ anthropologists still suffer from a tendency to want to locate pcople in defined tribes or other bounded units; despite the critiques of essentialism that have become standard fare in academic circles and that are particularly insistent in feminist theory, many feminist scholars con- 


\section{[182] Lesbian Mothers}

cerned with "difference" traffic in the same notions of deterministic boundaries that they seek to overturn. ${ }^{3}$

At first glance, the accounts of the lesbian mothers I interviewed reveal little about how lesbian mothers fit into the framework called for in the new research. I had hoped to show that lesbian mothers could be "normal," but I had not expected them to look quite so ordinary as they did as I listened to their accounts of day-to-day struggles in the world. I had looked for evidence that would help lesbian mothers facing persecution in the courts, and I had expected to find that they had devised uniquely adaptive cultural forms, something that I could perhaps call "lesbian-mother culture." What I found instead was creativity directed toward the complexities of negotiating identity rather than toward delineating bounded behavior or institutions particular to lesbian mothers.

Despite the many concrete differences that separate the experiences of lesbians and heterosexual women, whether they are mothers or not-most notably their vulnerability to the effects of heterosexism ${ }^{4}$ and stigma-I noted striking similarities in the language and imagery women of both groups chose to frame their experience, to explain themselves, to tell me what it felt like to live their lives. At first I viewed these similarities as deriving from fundamental, concrete areas of convergence in the lives of lesbian and heterosexual mothers. I considered the financial difficulties both groups face; I thought about their common struggles to keep their children's fathers in their lives, to find adequate housing, to locate reliable and affordable child care, to deal with their own loneliness, to manage conflicts between the demands of friends and children. But the similarities I listened to in the narratives of 135 mothers were not just about concrete realities; they were about meaning, and most specifically about the meaning of motherhood.

My findings show, I think, not that lesbian mothers resemble heterosexual mothers in a way that minimizes the importance of their lesbianism ${ }^{5}$ but that lesbian mothers, like other mothers, share in the system of meaning that envelops motherhood in our culture. I had asked all the mothers I interviewed to tell me about themselves, to tell me what being a mother meant to them, how they organized the 
activities mothers must undertake, what a mother is. And they did just that: they told me what a mother is in American culture.

These narratives did not, in the final analysis, describe accurately (or inaccurately) what women do on a day-by-day basis, how they actually spend their time, or what their relations with various categories of people-family, friends, children, ex-husbands, lovers-are "really" like. They told me what these relationships mean in the culture, and that lesbians, like other people, draw their meanings from the same repertoire of cultural possibilities.

Kath Weston's research on "families we choose"-the selfconsciously created kinship systems she learned about from gay men and lesbians in the San Francisco Bay Area-shows much the same process. ${ }^{6}$ Her informants, by casting their friendship ties in the mold of "family," by always contrasting the comfort they found in their "gay fanilies" with the problems they encountered in their "blood families," highlighted the continuing centrality of kinship as the model of intimacy, as the label appropriately applied to relationships that are permanent, reliable, unconditional, and accepting. Gay people she interviewed didn't reject the framework of family; they drew analogies from it, they created an understanding of the intimacy they had achieved with their friends from the meanings that surround kinship in our culture. Rather than build a new culture, they remodeled existing culture to fit their immediate needs.

Similarly, although the pro-choice and antiabortion activists whom Faye Ginsburg studied in Fargo, North Dakota, espoused antithetical political ideologies and were engaged in bitter struggle with each other, both groups of women claimed nurturance "as a central feature marking feminine identity in this culture" and construed it as an achievement. ${ }^{7}$ Their political stances, antagonistic though they were, were explained and made meaningful by a shared system of belief and identity.

So too with lesbian mothers. Lesbian mothers, like other mothers, select elements of their narratives from a circunscribed repertoire, a language of caring and nurturance, a language that makes motherhood supersede and engulf other aspects of identity. Unlike most people who subscribe to biologically derived gender ideologies, how- 


\section{[184] Lesbian Mothers}

ever, to whom motherhood is a natural attribute of all authentic women, lesbian mothers must consciously craft themselves into mothers. When motherhood is an achievement, it permits a woman to claim characteristics that are valued in American culture-independence and adulthood.

Highly elaborated and celebratory beliefs about motherhood and an emphasis on the ongoing structural significance of consanguineal ties are key elements of these mothers' long-term strategies, as they are for many women in poor American communities and in other situations that foster matrifocality. ${ }^{8}$ Kinship systems, for women in these circumstances, are arrayed around sets of lineal connections; elaboration of relationships with parents can serve to highlight the ongoing importance of ties to children. Just as kinship links one to one's parents, it establishes the continuing utility of ties to one's child. The central place of kinship in mothers' ideas about how to manage under adverse material conditions helps us to understand the seemingly contradictory stress they place on strengthening children's ties with their fathers. The fathers are the blood kin of children who are likely to need such connections in the future.

Though lesbians are still outsiders in American culture, the fact that they are mothers pulls them, however ambiguously, into a central position in the gender system. Resistance to the relegation of lesbians to the nonprocreative and hence nonwomanly domain thus constitutes a kind of accommodation to this gender distinction. At the same time, lesbians are perhaps more conscious of the need to craft thcir identities under these conditions; the "option" to become mothers that heterosexual women are expected to exercise is rarely readily available to lesbians.

\section{The Changing Climate}

Some political and social trends indicate that my initial concern with lesbian mothers' rights in custody disputes continues to be relevant. The New Right in its various guises has continued to oppose what its proponents perceive as challenges to gender and family forms they claim as "traditional." 9 They have been joined, in some unlikely 
coalitions, by liberals who also trace problems in Amcrican society to the "breakdown" of the family. An article in the New York Times of May I, I99I, reported, for example, on a coalition being formed by such figures as Phyllis Schlafly and Pat Schroeder, based on agreement that "strengthening the family is the best way to make progress on a number of domestic ills from drug abuse to poor achievements in education." 10 Coalition members seek, among other goals, to institute tax incentives and revisions in the divorce laws which would discourage couples with children from divorcing. Representative Dave McCurdy, one of the Democrats seeking to strengthen "profamily, moral values," is quoted as criticizing the platform on which the Democratic party has stood since the I 960 s as "the agenda of narrow and special interests. You had the formation of women's groups, and organizations like the Gay and Lesbian Alliance, and the pro-abortion and anti-abortion debate. The interests got so narrow, and the agenda got dictated by those narrow interests, and we lost sight of the broader principals and objectives."

Efforts of this sort assume that ongoing controversies over abortion, over child care and women's place in the labor force, and over the organization of families are basically moral debates. As Anna Tsing has hauntingly shown in her account of the public response to women accused of infanticide, they depend on underlying images of "good" (that is, altruistic, not sexual) and "bad" (that is, selfish, sexual) women and mothers, just as they do on shared concepts of what "good" and "bad" families are."1

As we have seen, they are also played out in custody disputes, a domain in which assumptions about the "good mother" are most dramatically deployed. No-fault divorce and gestures toward mechanical gender equity in adjudication of divorces have been institutionalized. ${ }^{12}$ Thus increasingly frequent custody disputes become the most accessible arena for public recitation of the attributes of good mothers and chastisement of "bad" mothers before the wider community.

But varying manifestations of the normalization of hightechnology reproductive interventions are perhaps most revealing of the continuing conservatism of the popular construction of mother- 
hood. Public discussions appear with deadly regularity over presumed conflicts between mothers' desires to protect their own welfare on the one hand and the well-being of their fetuses or children on the other. Drug cases, disputes over presumed reproductive hazards in the workplace, discussions of alcohol use during pregnancy, disputes about obstetrical interventions and consent to medical procedures, debates about surrogacy, all point to the assumption that motherhood is a special state that appropriately consumes all of a woman, obliterating her ability to make choices on behalf of her offspring, framing her interests and those of her offspring as inherently antithetical. ${ }^{13}$

The interplay between culture and technology in the domain of "heroic" or improbable pregnancies is most telling. I am thinking particularly of the possibilities of extending childbearing even into old age. On October 25, I990, the New York Times headlined an article on the use of donated eggs in experimental pregnancies "Menopause Is Found No Bar to Pregnancy."14 Some less futuristic scenarios are already in place as a range of other issues surrounding surrogacy and other extreme methods for "becoming" mothers move into ordinary discourse. The increasing routinization of these techniques, their leap out of the world of science fiction into daily life, and even into the reproductive repertoire of lesbians, tells us that even homosexuality offers no explanation for failure to achieve motherhood. Motherhood, it seems, takes up the slack as gender and sexuality no longer institutionalize each other.

But a number of other things also have happened since I began this work in the I 970 s. Whereas the existence of lesbian mothers then had barely penetrated public consciousness, these women have joined members of a wide range of other nontraditional family or household configurations in gaining a public face. While I was trying to make lesbian mothers visible, the rest of the world was already discovering them.

This was the period that witnessed not only the "lesbian baby boom" but the rise of a vocal movement for gay and lesbian rights. During these years the nation saw a proliferation of gay and lesbian parades and demonstrations (including the national march on Wash- 
ington in 1987 , which drew several hundred thousand participants); the "coming out" of several gay political figures, as well as campaigns for public office by open lesbians and gay men; debates over gay rights ordinances, domestic partners legislation, and other official policies; the growth of gay-oriented civil rights organizations and public-interest law firms such as Gay Rights Advocates and the National Center for Lesbian Rights; and extensive discussion in several religious denominations over the place of lesbians and gay men in congregations and among the clergy. These were also the years during which the AIDS epidernic forever changed the tone of all discussions of gay life, both intensifying the stigma already attached to homosexuality and humanizing the image of gay people to a wide and previously uninvolved audience. ${ }^{15}$

So-called postferninism seems also to be characterized by an acceptance of many previously unacceptable forms and behaviors at the same time that feminism appears to have abandoned its earlier critical position vis-à-vis the family and marriage. Judith Stacey, for example, has described the dizzying complexity of "postmodern" families in California's Silicon Valley. ${ }^{16}$ While some structural features of these families are nothing like those of the typical suburban family configurations of their parents' generation, their emotional bonds and the expectations that frame them are strikingly familiar. Colleen Johnson has documented much the same sort of functional resilience among families after divorce. ${ }^{7}$

Despite the efforts of activists on the right, then, some populations defined as outside the "traditional" forms have come to redefine themselves and to achieve some acceptance as insiders. Many gay men and lesbians have developed a new sense of entitlement to the same kinds of privileges and legitimacy heterosexuals enjoy. ${ }^{18}$ No longer seeking mere tolerance, some lesbians and gay men are demanding that their relationships be recognized as morally and even legally equivalent to more conventional forms: they want to be able to marry. ${ }^{19}$

The issues that surround these shifts are not clearly either cultural or economic; it is difficult to tease apart the extent to which marriage and family are valued primarily because of the cultural legitimacy 
they entail or because of the financial advantages they confer. Philosophical arguments about "legitimacy" and "equality" become particularly strained when the stakes involve significant benefits such as health insurance. It appears, then, that we may be witnessing less the burgeoning of new family forms that Stacey has proposed than a shift in the ways comparatively marginal groups stake their claims to existing cultural and material resources, a particularly vital strategy as resources become increasingly scarce.

These developments involve parallel and apparently contradictory constructions of gender. While it appears that we are experiencing an expansion of our view of what kinds of people can reproduce or constitute a family, we are also witnessing a contraction of popular notions about how families live their lives.

Consider some newspaper headlines, all from I9go: "New Spin on the American Family: Gay, Straight Parents Share Joys, Chores" (Oakland Tribune, June 20); "Lesbian Custody Fights Test Family Law Frontier" (New York Times, July 4); "Suit Over Death Benefits Asks: What Is a Family?" (New York Times, September 2I). Most simply, these headlines tell us that something called the "lesbian and gay family" has captured the popular imagination, adding a new element to the longstanding discussion (or lamentation, depending on your point of view) of how traditional family forms may be changing. The language of these and similar articles that appear periodically in the mainstream press reminds us that unusual sorts of people are claiming legitimacy for their "families," but that the standard of comparison in all of these situations remains the "normal" heterosexual two-parent family, or at least what most people imagine it to be.

If the discussions of these "new" kinds of families in the media indicate that their status has been somewhat normalized, it is also true that little new is actually described. Formidable symbols of conventional (read "natural") family life are presented to back up claims that families headed by lesbian or gay parents are, in fact, families like any others. A woman who is suing her deceased lover's employer for death benefits tells the reporter that their life together was "as much a marriage as any heterosexual union," citing a ceremony they held to formalize the union and the fact that they had purchased a home and 
raised the children of the surviving partner together ${ }^{20}$ An article about a lesbian mother, her sperm donor-co-parent, and their young son begins with an image of the child playing with wooden trains and a stuffed dog. In describing the co-parenting arrangement the lesbian mother has made with a heterosexual man, the article further evokes normality by describing their joint participation in Jewish holiday celebrations, family vacations, and the boy's trips to visit his paternal grandparents. Because the father is in the picture as an active parent, this family seems less deviant than those created with anonymous donors, and much is made of this difference in the article. The director of a local sperm bank is quoted as saying, "There is a real shift in how lesbians are defining family. Ten years ago, it would have been lesbians raising a child, preferably a female child. Now that preference doesn't seem to be stated as strongly. More and more lesbians are seeking out men who want to play some role in their child's life. At that point, I'm not so sure we can still call the person a donor."21

At the same time, "traditional" images of family and kinship are revived in articles about visitation disputes between lesbian biological mothers and their former partners. The biological mothers are apt to retreat into conventional notions of kinship and parenthood to invalidate the former lover's claims to continuing involvement with the children. The former lover's claims, while based on the assertion that biological ties are not the only kind that forge parental bonds, finally depend on images of behaviors that conventionally constitute parenthood.

In a case described in the New York Times of July 4, I990, Michele G, who is suing her former partner, Nancy $S$, for the right to visit the two children she calls her son and daughter, says, "These judges don't understand what it is to be a mother. To sit there and say with a straight face that someone who has stayed up all night nursing a child, swabbing her chicken pox, taking joy in her every advancement, picking her up every time she's skinned her knee, or singing her to sleep is not a "mother' is an absurdity." But the lawyer for the biological mother says, "These children were produced by Nancy, and Michele is not the legal or biological anything to them."22

The final decision in this case was reported in the New York Times 


\section{[190] Lesbian Mothers}

of March 24, I99I. The state appeals court denied all custody and visitation rights to Michele because "her status was not the same as a biological or adoptive parent." A decision to expand "the definition of a 'parent' in the manner advocated" could expose "other natural parents to litigation brought by child-care providers of long standing, relatives, successive sets of step-parents, or other close friends of the family." 23 So while the legitimacy of the family formed by a lesbian mother through artificial insemination is affirmed, the former partner is not seen as the noncustodial parent in the way that a former husband would be.

\section{Motherhood and Womanhood}

What do these developments suggest about my efforts to show that lesbian mothers are "as good as" heterosexual single mothers, or at least not definably different? When my intervicws consistently yielded familiar domestic scenarios, I first thought my job was essentially over. It seemed that I had found pervasive similarities berween lesbian mothers' and heterosexual mothers' accounts of their lives, and could thus substantiate my claims that lesbian mothers deserved social recognition and legal protection.

As my analysis progressed, I found that these similarities could be explained less readily as the products of adaptation to similar circumstances than as aspects of a common cultural process. It became clear that lesbian mothers' stories focused on establishing claims to motherhood and on affirming motherhood as a central identity, whether they were describing how they became mothers, their relationships with their children, or how they organized their ties with their relatives. They thus showed how achieving motherhood can enable them to share in its meanings without submitting to implications of biological inevitability. By being lesbians and being mothers, the women I interviewed revealed a complicated strategy that moved between resistance and accommodation.

But lesbian (and heterosexual) mothers' narratives tell us something even more interesting, and more significant in terms of some of the directions the politics of reproduction are taking in the last years 
of the twentieth century. What these narratives tell us, over and over again, is that motherhood and womanhood continue to be conflated and mutually defined. At the same time that the emergence of all sorts of nontraditional family forms suggests that something is changing and that conventional limitations on sexuality seem to be retreating, the continuing location of motherhood at the defining edge of gender necessarily sabotages those changes. ${ }^{24}$ Lesbians are no longer automatically denied access to the system of meanings we call "motherhood"; rather, they now have the possibility of choosing motherhood (whether the choice is to become a mother or to derive one's identity from being a mother), and thereby gaining access to "womanhood" through negotiation. While the category of "woman" thus expands, the definitions associated with it do not. "Women" arc still mothers (or potential mothers). Non-mothers are still not quite women, though heterosexual women without children are more easily perceived as on the way to becoming mothers. To the extent that (presumed) heterosexuality is linked, at least in the imagination, to reproduction, heterosexual childless women are less likely to find their claims to womanhood in question, at least while their fertility remains intact. In fact, if developments in popular culture can be said to offer a reflection of social mores, even the lack of a husband is no longer viewed as an impediment to achieving motherhood. An article in the New York Times of October I6, I9gI, enumerated television programs that featured "older" (in their thirties or forties) single women. In just one season no fewer than seven of these shows developed plot lines in which their heroines contemplated or carried out insemination in defiance of the "biological clock," generating a veritable epidemic of out-of-wedlock pregnancy. ${ }^{25}$ The message conveyed by these story lines is complex, to be sure, but can probably to taken to suggest not only that singleness and advancing age need not impede motherhood but that they provide no excuse for failing to do so.

Neither, it seems, does the fact that one is a lesbian. Whereas I had assumed that the very existence of lesbian mothers posed an implicit challenge to the hegemonic family criticized by Second Wave feminism, the revelation of similarities between lesbian and heterosexual mothers can threaten to nourish a trend that accords more value to 


\section{[192] Lesbian Mothers}

mothers than to women who have no children, regardless of their sexual orientation.

Certainly by becoming mothers lesbians can gain access to the same intrinsic rewards motherhood offers other women. But motherhood also allows lesbians to claim membership in the group known as "women" on the same basis as heterosexual single mothers, rather than because of the stigma they share as women in the workplace and on the streets. The otherness of childless lesbians may be intensified not because they are lesbians but because they are not mothers. Like gay and lesbian marriage, the new access to traditional womanhood can divide lesbians and gays on the basis of respectability. At the same time, motherhood continues to divide women into two groups with different cconomic opportunities, different social status, and possibly conflicting political interests.

But perhaps a deeper question to be addressed is why we hear more about lesbian mothers today than we used to. On one level, their emergence into mainstream visibility points to the growing pride and sense of entitlement and legitimacy that lesbian and gay people in America have gained, as demonstrated by decreasing levels of secrecy and new symbols of acceptance. But on another level, this change may reflect the further calcification of the old construction of gender in terms of motherhood and the simultaneous defusing of the threat to traditional gender categorics the lesbian and gay movement and feminism seem to have achieved. For this reason, it suggests some rather ominous scenarios for reproductive politics. We may, in fact, be moving into an era in which class will be based not on the mcans of production, but on the means of reproduction, with mothers and nonmothers poised against each other in conflict not only over diminishing resources but over contested meanings of gender. 